\title{
南极海洋保护区事务的发展及挑战
}

\author{
付玉 \\ （中华人民共和国自然资源部海洋发展战略研究所，北京 100161）
}

\begin{abstract}
摘要: 南极海洋保护区事务近 10 年来发展较快, 是南极海洋治理中备受关注的重点议题。本文介绍了南极海洋保护区的设 立进程, 探讨了南极海洋保护区事务面临的挑战, 提出了中国参与南极海洋治理的建议。南极海洋生物资源养护委员会各成 员方在南极海洋保护区法律制度、政治因素、科学基础和管理监测等方面仍存在分歧和矛盾, 是南极海洋保护区事务进一步 发展的主要挑战。为实施 “海洋命运共同体” 重要理念, 履行南极海洋生物资源养护委员会成员国义务, 中国应深度参与南 极海洋保护区事务、尽快完善国内海洋保护区法律制度, 并大力加强南极海洋生态环境科学研究。
\end{abstract}

关键词: 南极海洋保护区; 南极海洋治理与养护; 科学数据

中图分类号：DF90 文献标识码：A

\section{Development and Challenges of Antarctic Marine Protected Areas}

\section{Fu Yu}

(China Institute for Marine Affairs, Ministry of Natural Resources of the PRC, Beijing 100161, China)

\begin{abstract}
The Antarctic marine protected areas (MPAs) have developed rapidly in the past decade and are the focus of ocean governance in the Antarctic, attracting much attention. This paper introduces the establishment process and legal basis of the Antarctic MPAs, discusses the challenges in the development process, and raises some policy proposals. Some disagreement and controversy remain among the members of the Commission for the Conservation of Antarctic Marine Living Resources (CCAMLR) in terms of legal regime, political issues, scientific basis, management, and monitoring, which are the major challenges in the development of Antarctic MPAs. In order to implement the important concept of "Marine Community of Shared Future" and fulfill the obligations as a member of CCAMLR, China should deeply participate in the affairs of the Antarctic MPAs, improve domestic legal regime on MPAs, and strengthen scientific research on marine ecology and environment of the Antarctica.
\end{abstract}

Keywords: Antarctic marine protected areas; Antarctic ocean governance and conservation; scientific data

\section{一、前言}

南极海洋保护区事务是南极海洋治理的重点
议题。自 2004 年以来，南极海洋保护区事务在南 极海洋生物资源养护委员会 (以下简称 “委员会”) 体系下快速发展, 成为公海保护区发展最快、最受

收稿日期 : 2019-08-10; 修回日期 : 2019-10-18

通讯作者: 付玉, 中华人民共和国自然资源部海洋发展战略研究所副研究员, 研究方向为海洋政策与管理、全球海洋治理; E-mail: fuyu@cimamnr.org.cn

资助项目：中国工程院咨询项目 “海洋强国战略研究 2035” (2018-ZD-08); 国家社科基金 “新时代海洋强国建设” 重大研究专项项目 “提升 我国在国际涉海事务中的话语权和制度性权利研究” (18VHQ006)

本刊网址：www.engineering.org.cn/ch/journal/sscae 
瞩目的区域，拥有世界上第一个完全位于国家管辖 范围以外的南奥克尼群岛海洋保护区和面积最大的 罗斯海保护区。根据 “委员会” 有关规划和发展态 势, 未来 10 年间海洋保护区网络将遍布南极海域。

中国是南极活动大国, 是南极条约体系 “和 平、科学、保护” 核心价值的积极拥护者。中国于 2006 年批准《南极海洋生物资源养护公约》(以下 简称 “CAMLR 公约”), 次年成为 “委员会” 成员国。 在中国作为正式成员国参加 “委员会” 会议时, 在 “委员会” 机制内建设南极海洋保护区已基本形成 定论。中国在科研、外交和法律等方面开展了大 量基础性工作, 逐渐扭转了在南极海洋保护区事务 中的被动地位, 成为南极海洋保护区进程的积极参 与者, 将为夯实该进程的法律依据、科学基础和管 理监测等做出更多贡献。

《南极条约》(签署时间 1961 年 6 月 23 日) 暂 时冻结了各国对南极大陆的主权要求, 南极大陆周 围的海域一般被当作公海看待, 在该海域建立的海 洋保护区被视为公海保护区。本文仅讨论 “委员会” 在其管辖的南大洋海域范围内设立的公海保护区, 不涉及英国、南非和法国在其所属亚南极岛屿周围 建立的、位于 “委员会” 管辖范围内的海洋保护区。 就定义而言, “委员会” 认为海洋保护区是全部或 一部分自然资源能够得到保护的海域, 为实现特定 养护措施、生态环境保护、生态系统监测或者渔业 管理等方面的目标, 在该海域内的某些活动受到限 制或者被完全禁止。

\section{二、南极海洋保护区的设立进程}

“委员会”于 2004 年要求其科学委员会将海洋 保护区作为优先工作 [1], 开始推动在南极海域建 立海洋保护区, 至今已设立两个海洋保护区, 占全 世界公海保护区数量的一半, 另有 3 个海洋保护区 提案正在开展磋商讨论。根据 “委员会” 于 2011 年 10 月通过的南极海洋保护区规划, 将逐渐在整个南 极海域建成海洋保护区网络 [2]。

\section{（一）已建南极海洋保护区}

南极海洋保护区事务在 “CAMLR 公约” 框架 下开展, 由根据该公约成立的 “委员会” 负责开展 相关工作。该委员会目前有 26 个成员方, 包括美国、
澳大利亚、新西兰、俄罗斯、法国、日本和中国等 南极活动大国以及欧盟。根据养护海洋生物资源的 职责和目标, “委员会”已在南大洋海域建立了南 奥克尼群岛南大陆架海洋保护区和罗斯海保护区。

1. 南奥克尼群岛南大陆架海洋保护区

2009 年 11 月, “委员会” 第 28 届大会决定设 立南奥克尼群岛海洋保护区, 制定了专门的养护措 施（CM91-03)。该保护区位于南极半岛东部的凹 形区域, 面积约为 $9.4 \times 10^{4} \mathrm{~km}^{2}$ 。设立该保护区的 目标是限制区域内过度的捕鱼活动, 保护信天翁、 海燕、企鹅和南极海狗等海洋生物。图 1 为南奥克 尼群岛南大陆架海洋保护区地理位置和边界。

南奥克尼群岛海洋保护区的养护措施包括: (1)禁止一切捕鱼活动。为监测或其他目的开展的科 研活动, 需取得 “委员会” 同意, 并遵守保护区内 的养护措施; (2)禁止一切渔业船只（包括渔船、渔 船补给船、渔业加工船、渔业运输船等) 在该区进 行任何形式的倾废排污, 禁止渔船转运; (3)为监测 保护区内的交通情况, 鼓励船只在途经该区前将其 船旗国、船只大小、国际海事组织 (IMO) 编号、 途经路线等信息通知 “委员会” 秘书处。南奥克尼 群岛海洋保护区在设立和运行 10 年后仍存在一些 问题, 最大的问题在于严重缺乏科学监测数据, 无 法评估保护绩效 [3]。

\section{2. 罗斯海保护区}

罗斯海保护区由美国和新西兰于 2011 年各自 单独提出, 于 2012 年合并为一个联合提案。提案 提出后，“委员会”成员国围绕罗斯海保护区的 面积、科学性、必要性和保护期限等要素进行了 激烈博弯。牵头推动设立该保护区的西方国家综 合利用政治、外交、科学和舆论等多种方式, 于 2016 年促成 “委员会” 通过了该提案。罗斯海保护 区正式设立后在管理方面进展缓慢, 至今未通过科 研与监测计划 [4]。

\section{(1) 罗斯海保护区的区域}

罗斯海是南太平洋深入南极洲的大海湾, 位 于罗斯陆缘冰之北。罗斯海保护区保护面积达到 $1.55 \times 10^{6} \mathrm{~km}^{2}$, 是目前世界最大的公海保护区, 其 中 $1.12 \times 10^{6} \mathrm{~km}^{2}$ 得到充分保护。罗斯海保护区的 有效时间为 35 年, 持续到 2052 年。该保护区分 为 3 个区域: (1)不允许商业捕鱼的普遍保护区（约 占保护区的 $72 \%$ )；(2)磷虾研究区（约占保护区的 


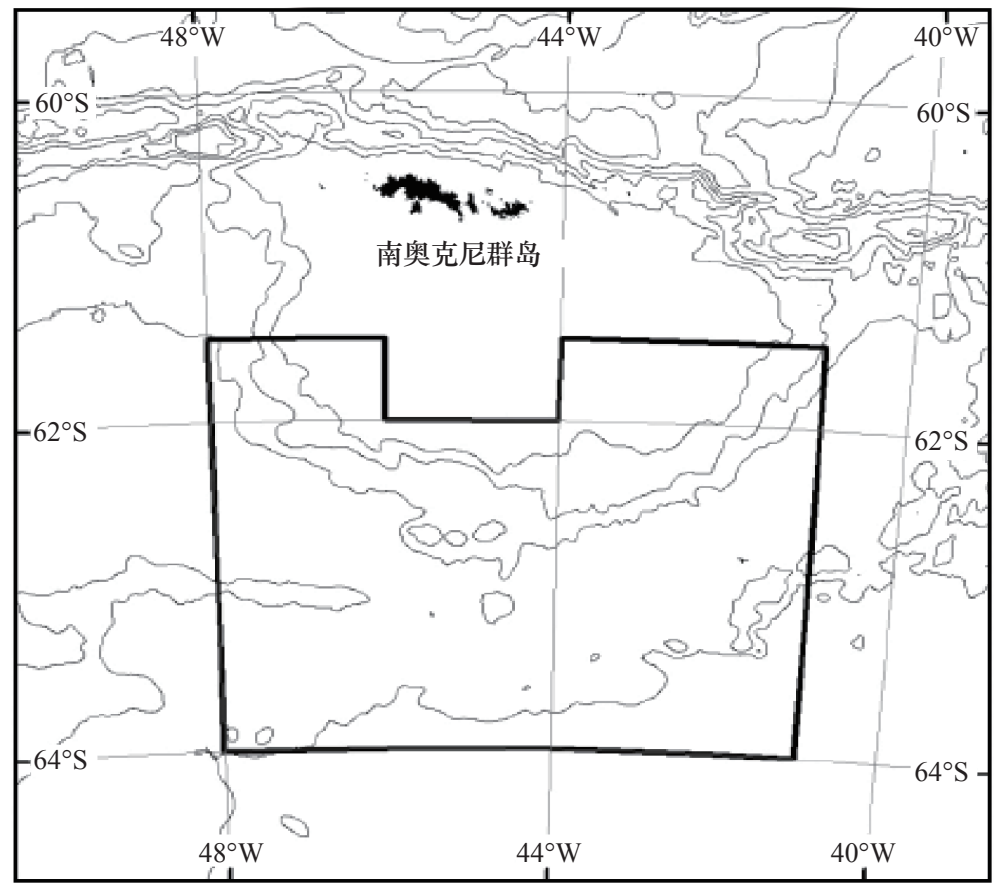

图 1 南奥克尼群岛南大陆架海洋保护区地理位置和边界

注：图片来源于 Commission for the Conservation of Antarctic Marine Living Resources. Protection of the South Orkney Islands Southern Shelf, Conservation Measure 91-03 (2009)。

$21 \%$ )，允许磷虾的监管捕捞; (3)特别研究区（约 占保护区的 7\%), 允许有限的捕鱼活动。罗斯海保 护区的区域设置体现出相关国家间的政治妥协，例 如特别研究区原为新西兰的重要犬牙鱼渔场，为适 当顾及新西兰的渔业利益而允许一定量的捕鱼活 动。而且，生产力最高的犬牙鱼渔场，如艾斯林滩， 被排除在保护区之外 [2]。

(2) 罗斯海保护区的主要保护对象和目标

罗斯海保护区的主要保护对象为罗斯海独特的 生态系统, 重点保护物种为犬牙鱼和磷虾。设立保 护区的主要目标为: (1)保护罗斯海地区的生物结构 和生态功能, 通过保护栖息地, 对当地的哺乳动物、 鸟类、鱼类和无脊椎动物进行必要的保护; (2)提供 濒危鱼类种群的研究资料, 更好地研究气候变化对 鱼类生态效应的影响, 提供更好的研究南极海洋生 物系统的机会; (3)对南极犬牙鱼的栖息地提供特殊 保护; (4)保护磷虾。

(3) 罗斯海保护区的运作和保护手段

罗斯海保护区的保护手段主要有：(1)分区管 理, 将罗斯海保护区分为 3 个区域, 实行不同的管 理措施; (2)采取禁渔和限制捕捞的措施; (3)对渔船 进行管理, 要求进出罗斯海保护区的渔船报告, 并
限制渔船在保护区内转运。罗斯海保护区规定了较 为详细的报告义务, 成员国每五年应向 “委员会” 秘书处提交一份与海洋保护区科研与监测计划有关 活动的报告, 由科学委员会负责审查。罗斯海保护 区管理措施还包括鼓励 “委员会” 成员国就该保 护区的所有活动和执行情况采取相应的监察和监督 措施 [5]。

（4）罗斯海保护区的管理机制

罗斯海保护区在决策机制上主要依赖于 “委员 会”、科学委员会、秘书处及成员国的协作，其中 “委员会” 具有建立罗斯保护区的决策权, 同时也 有权制定发布相关的管理措施。科学委员会的职能 主要是审议保护区提案的科学基础并向 “委员会” 提供建议, 审查和评估相关研究计划和活动; 秘书 处负责行政事宜; 成员国有向 “委员会” 报告其 在海洋保护区进行活动的义务。图 2 为罗斯海保 护区地理位置和边界。

\section{（二）南极海洋保护区事务发展态势}

2011 年 10 月, “委员会” 第十三届科学委员会 会议通过了一项南极海洋保护区区域规划，是南极 海洋保护区设立的规划依据和蓝图（见图 3)。该规 


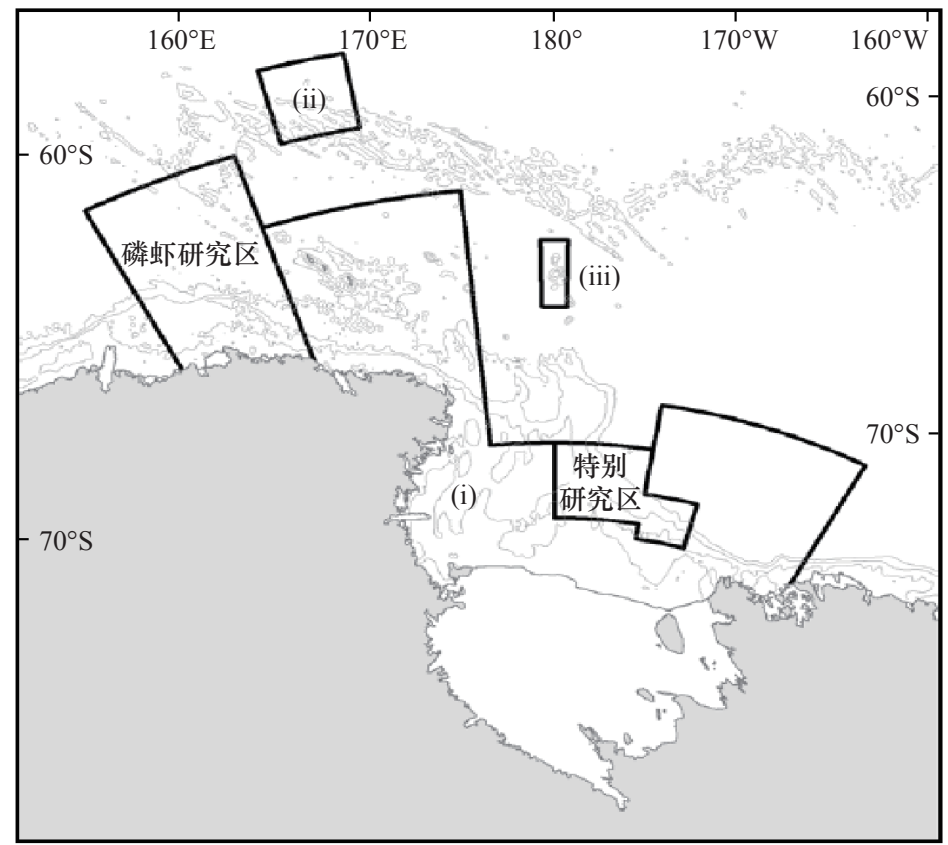

图 2 罗斯海保护区地理位置和边界

注: 图片来源于 Commission for the Conservation of Antarctic Marine Living Resources. Ross Sea Region Marine Protected Area, Conservation Measure 91-05 (2016)。

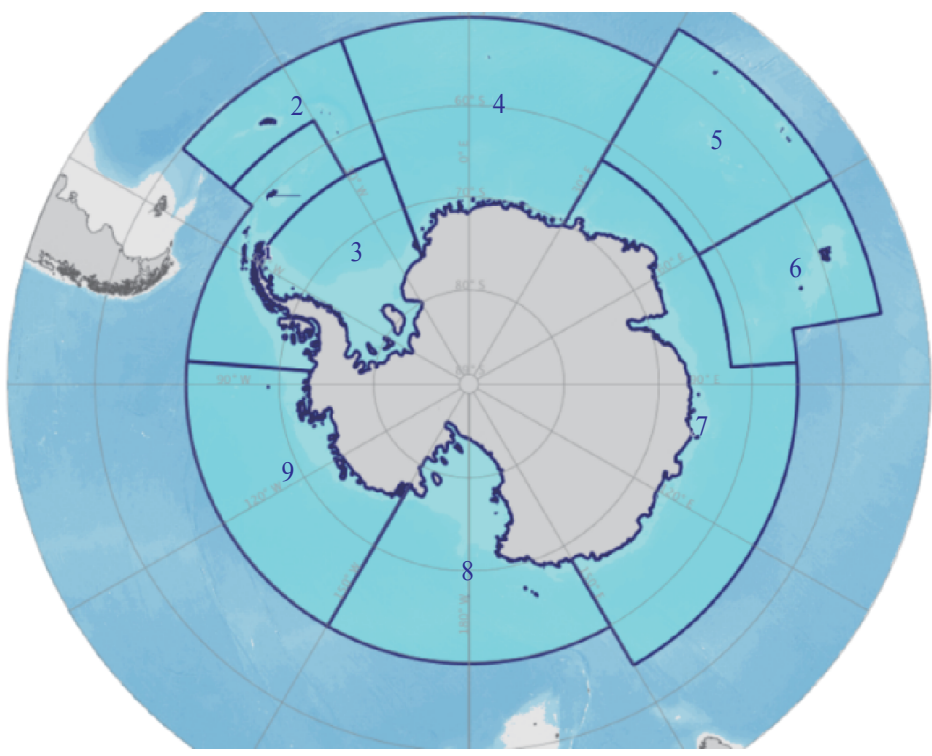

图 3 南极海洋保护区规划区域

注: 图片来源于 Commission for the Conservation of Antarctic Marine Living Resources. MPA Planning Domains。

划将全部南极海域划分为 9 个区域。从规划及目前 发展态势看, 未来所有南极海域各分区都将设立南 极海洋保护区。

“委员会” 在推动南极海洋保护区建设方面, 突 破了 “CAMLR 公约” 所规定的目标与职能, 越来 越多地向生物多样性和生态系统养护的环境保护组 织接近, 从而改变其渔业管理组织的性质。“CAMLR 公约” 第二条明确了公约的目的是养护南极海洋
生物资源。第九条是对第二条的具体实施, 规定 “委员会” 在养护和管理南极海洋生物资源方面的 权能。从第二条和第九条的规定可见, “CAMLR 公约” 本质上仍是传统的以生物资源利用为中心的 条约, 体现了国际海洋法关于平衡公海生物资源养 护与可持续利用的精神, 只是在原则上更加强调生 态系统与预防性 [2]。但在海洋保护区实践中，南 极海洋保护区的目标和养护措施均已扩大到对生态 
系统和生物多样性的养护。主要提案国在 2014 年 “委员会” 会议上发表声明, 一致认为为养护渔业 资源而采取的区域管理措施不是 “委员会” 设想 的保护区，保护区应该能够实现海洋生物多样性 养护的目的。

\section{（三）正在讨论的海洋保护区提案}

除以上 2 个已设立的海洋保护区之外, 目前有 3 个保护区提案正在 “委员会” 开展碰商讨论。分 别是法国和澳大利亚于 2012 年提交的东南极海洋 保护区提案（2018 年提案方变为澳大利亚和欧盟）、 欧盟于 2015 年提交的威德尔海保护区提案, 以及 阿根廷和智利于 2018 年提交的南极半岛海洋保护 区提案。

\section{1. 东南极海洋保护区提案}

东南极海洋保护区提案是由法国和澳大利亚在 2011 年第 30 届 “委员会” 会议上提出的, 在其后 历届会议上经过了多次讨论和修改。该提案所涉及 的南极东南部海域具有丰富的生物和矿物资源。据 初步勘察, 东南极海域蕴藏大量油气资源和锰结 核, 该海域的海湾存在着大量冰架, 蕴含丰富淡水 资源。在生物资源方面，东南极海域物种丰富，栖
息着大量海豹和海鸟。经过多次修改后, 提案的规 划范围和管理制度均发生了变化。在 2015 年第 34 届 “委员会” 会议上，提案国将之前规划的 7 个海 洋保护区区块减至 3 个，但表示并不放弃其他 4 个 区块。在 2019 年第 38 届 “委员会” 会议上, 由 于成员方在科学数据、保护边界和目标等方面仍存 在分歧, 该提案未获得通过, 需要继续修改讨论。 图 4 为东南极海洋保护区提案规划图。

\section{2. 威德尔海保护区提案}

威德尔海保护区提案由欧盟及其成员国于 2016 年提出。根据该提案, 威德尔海保护区将由两 块不相连的海域构成, 第一块海域大致在南极半岛 东北海岸向东部延伸，呈现 “凹” 字状; 第二块海 域大致沿南极大陆向北延伸, 包括部分冰架和岛屿。

威德尔海保护区的主要目的为保护生物多样性 和栖息地, 建立科学参考区域, 以监测气候变化、 捕捞和其他人类活动的影响, 特别是研究海洋生态 系统以及具有代表性的、罕见的、独特的生物多样 性和栖息地，增强其适应能力和适应气候变化影响 的能力等。为实现上述保护目标，威德尔海保护区 提案设计提出 3 种保护区类型：普遍保护区(GPZ)、 特别保护区 (SPZ) 和渔业研究区 (FRZ)。普遍保

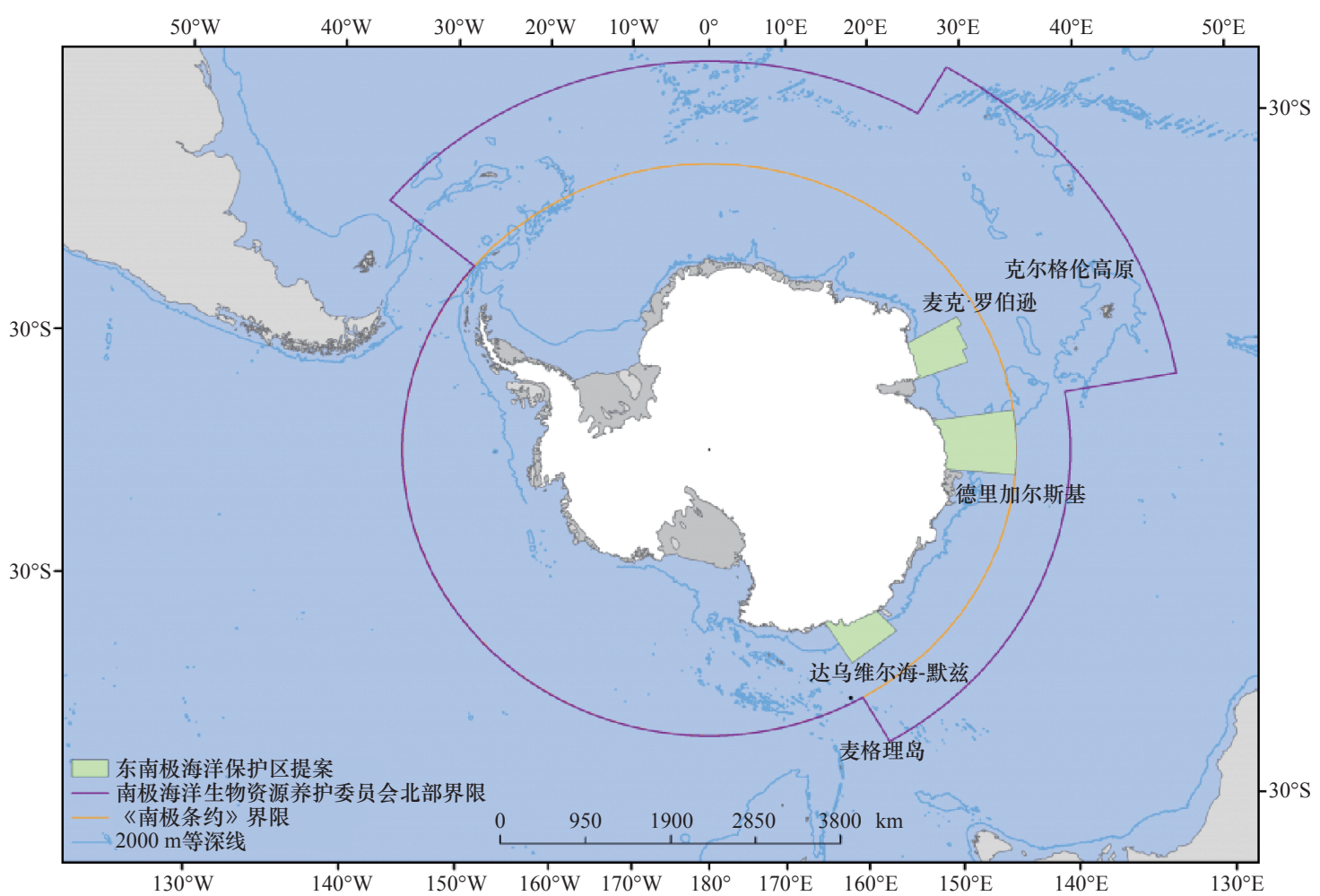

图 4 东南极海洋保护区提案规划图

注: 图片来源于 Marine Protected Area for East Antarctica. Australian Government。 
护区面积最大, 特别保护区分布于普遍保护区内, 而渔业研究区则分布于南极大陆沿岸。提案特别指 出, 威德尔海保护区的具体面积和设立期限需 “委 员会” 会议讨论后决定。威德尔海保护区提案覆盖 面积巨大, 且包括了人类在南极区域活动最多的南 极半岛海域周围, 其对南极活动的潜在影响值得密 切关注。

\section{3. 南极半岛海洋保护区提案}

在 2018 年的 “委员会” 会议上, 阿根廷和智 利提出了在规划区域 1 建立南极半岛海洋保护区 (D1MPA) 的提案。该提案区域位于南极大陆西北 部的南极半岛附近。该提案的保护目标包括有代表 性栖息地、生态系统过程、物种生命周期重要区域, 以及稀有的、脆弱的生态系统等。

\section{三、南极海洋保护区事务面临的挑战}

整体来看, 南极海洋保护区事务虽取得重要阶 段性进展, 但在法律制度、政治支持、科学基础和 管理监测等方面仍存分歧和矛盾, 是南极海洋保护 区事务进一步发展的主要挑战。“委员会” 和各成 员方应重视海洋保护区制度建设中存在的法律、科 学和管理问题, 积极回应和解决政治关切, 促进南 极海洋保护区建设向着公正、透明、科学、务实的 正确方向发展, 以利于南极海洋生物和生态的长期 有效养护。

\section{（一）法律制度不清晰}

目前规范公海保护区建设和管理等问题的统一 法律框架尚未形成, 与公海保护区议题相关的国际 条约及规范性文件数量较多 [6], 但普遍缺乏针对 性和适用性。区域性条约是目前公海保护区设立和 管理的最主要、最直接的法律依据。

1980 年 “CAMLR 公约” 和根据该公约设立的 “委员会” 制定的有关措施规定是设立南极海洋保 护区的直接法律依据。“CAMLR 公约” 第九条是 “委员会”划定保护区和采取相应生物资源管理措 施的依据。该条规定, “委员会” 有权根据养护需 求, 以现有的最佳科学论证为依据, 制定、通过和 修订养护措施。2011 年, “委员会” 制定通过了《关 于建立 CCAMLR 海洋保护区的总体框架》 (以下简 称《总体框架》), 是 “委员会” 对 “CAMLR 公约”
第九条有关划区保护规定的补充和完善 [7]。

《总体框架》简要阐述了在 “CAMLR 公约” 区 域内建立海洋保护区的法律渊源、制度背景和科学 理论依据, 制定了建立海洋保护区的目标、要件、 程序、适用对象和审查评估制度等形式要件。因制 定时间仓促和经验不足等原因, 《总体框架》仍然 存在缺陷。在通过《总体框架》之时, “委员会” 成员国对海洋保护区的定位、目标、科学依据仍然 存在分歧; 对构成海洋保护区的关键组成部分尚未 进行深入讨论和探索, 如本底数据、管理计划、科 研和监测计划等; 建立海洋保护区的科学方法、科 学指标和标准体系、数据收集分析和处理制度缺失; 在海洋保护区的概念、合理利用的概念和范围、保 护区具体目标与 “CAMLR 公约” 第二条的关系等 重大实体问题方面, 缺乏合理界定和总体设计。这 些是导致各成员方在海洋保护区问题上产生分歧的 主要原因 [8]。

\section{（二）政治争论不休}

南极海洋保护区事务在发展过程中, 对于海洋 保护区与南极主权主张之间的联系引发政治争论和 疑虑。俄罗斯于 2014 年向 “委员会” 提交一份工 作文件, 质疑南极陆地领土主张国利用海洋保护区 在其主张区域建立地缘政治控制 [2]。澳大利亚、法 国和新西兰等领土主张国对此予以否认。但不可否 认的一个事实是, 南极海洋保护区提案国的南极陆 地领土主张扇面所对应海域与提案所涉海域高度重 合。新西兰、澳大利亚、智利和阿根廷所提海洋保 护区提案所涉海域全部位于各自南极陆地领土主张 所对应海域 (见图 5、图 6)。欧盟所提出的威德尔 海保护区提案与挪威的南极陆地领土主张所对应海 域有重叠, 挪威对此提案提出异议。《南极条约》虽 暂时冻结了南极大陆领土主张, 但并未否定这些主 张, 主张国也没有放弃其主张。在 7 个南极大陆 主权主张国中, 澳大利亚是距离南极最近的国家之 一, 也是提出领土要求面积最大的国家。2004 年, 澳大利亚在向联合国外大陆架界限委员会提交的 $200 \mathrm{n}$ mile ( $1 \mathrm{n}$ mile $=1.852 \mathrm{~km})$ 外大陆架申请中, 就包括了澳大利亚 “南极领土” 的外大陆架 [9]。 在此种敏感情况下, 南极海洋保护区与领土主张和 地缘控制之间的关系成为政治猜忌和争论的重要原 因 [10]。 


\section{(三) 科学数据不足}

科学数据是南极条约体系养护和管理南极资源 的基础, 也是构建海洋保护区的基础和依据。1980 年 “CAMLR 公约” 进一步强调科学的重要性, 用风险 预防方法和生态系统方法管理南极海洋生物资源捕 捞活动 [11]。《总体框架》规定南极海洋保护区应 建立在最佳科学证据基础上, 要求 “委员会” 充分 考虑科学委员会意见。

在南极海洋保护区事务中, 对 “最佳科学证 据” 的解读与适用, 海洋保护区的科学依据是否足 够支撑其建立、养护和管理等，是 “委员会” 海洋 保护区磋商中一个贯彻始终的议题。2011 年, 美国 和新西兰分别向科学委员会提交了关于在罗斯海区 域建立海洋保护区的提案, 澳大利亚和法国向科学 委员会联合提交了关于在东南极区域建立代表性海 洋保护区体系的提案。科学委员会围绕罗斯海和东 南极两个海洋保护区提案的科学依据展开讨论时, 各成员间（包括提案国之间）在建立海洋保护区的 科学依据和政策目标方面产生了严重分歧。2019 年 10 月，在 “委员会” 第 38 届会议上，此时罗斯海 保护区已正式设立两年但未就该保护区的科研和监 测计划达成一致。中国针对罗斯海保护区科研和监 测计划提交了一份工作文件，强调该计划对于收集 整理分析保护区数据, 促进保护区的管理和评估具 有重要意义。建议在制定科研和监测计划时, 重视 本底数据, 并把养护目标和一般性规定转化成具体 的、可衡量的、可实施的管理目标。由于对东南极 海洋保护区提案的科学数据仍存异议, 主要包括本 底数据充足性、保护目标和参数等, 东南极海洋保 护区提案未获得通过，需要在将来 “委员会” 大会 上继续讨论 [4]。

\section{（四）有效管理缺位}

由于南极海域面积辽阔、气候恶劣、人类活动 相对较少、“委员会” 不具备监测执法力量等原因, 海洋保护区无法实现有效管理和监测。突出表现在 南奥克尼群岛海洋保护区在设立和运行 10 年后仍 存在一些问题，包括保护区的报告制度未得到很好 落实, 海洋保护区的养护措施单一, 主要是禁渔, 成效有待观察，保护区内的执法权有限等。在制度 实施方面，“CAMLR 公约”规定了观察员和检查 员有权进行检查，但是检查后即使发现相关船舶从

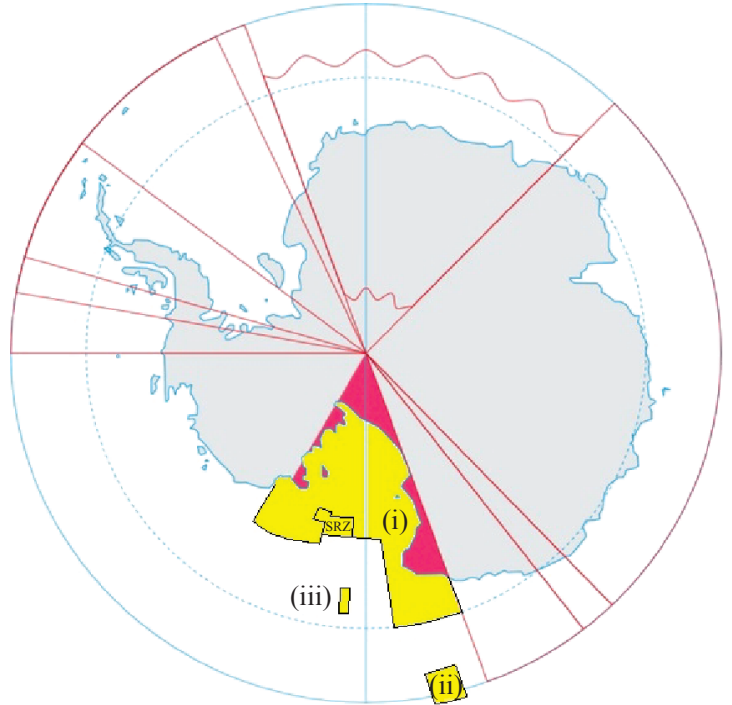

图 5 新西兰领土主张与罗斯海保护区对应情况示意图 注：粉色区域为新西兰南极陆地主张区域，黄色区域为新西兰作为提案国 所建立的罗斯海保护区（制图者冯羽）。

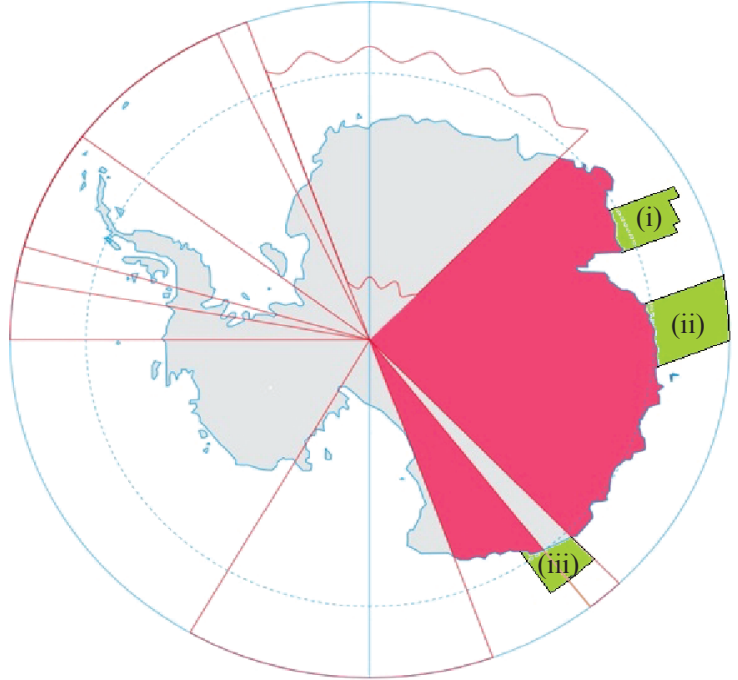

图 6 澳大利亚领土主张与东南极海洋保护区提案区域 对应情况示意图

注: 粉色区域为澳大利亚南极陆地主张区域, 绿色区域为澳大利亚提出的 东南极海洋保护区提案所在海域（制图者冯羽）。

事违法活动，观察员和检察员只能通报船旗国处理， 不能直接采取执法措施，使执法成效大打折扣。

\section{（五）养护与合理利用之争}

在南极海洋保护区设立进程中，养护与合理利 用的关系涉及海洋保护区的目标和理念, 是争论焦 点之一。“CAMLR 公约” 第二条明确了其目的是 “养护南极海洋生物资源”，“养护”一词包括合理 利用 [1]。“委员会” 制定的《总体框架》(2011 年) 亦明确南极海洋保护区 “应充分考虑 CAMLR 公约 
第二条关于养护包括合理利用的规定”。中国和俄 罗斯重视养护与合理利用海洋生物资源的平衡, 认 为海洋保护区提案对渔业活动的限制措施应具有充 分证据。新西兰作为罗斯海保护区的提案国则认 为, 罗斯海提案已经对边界进行了调整, 最大限 度地减少对渔业的影响, 而且提案中的特别研究 区就是为了兼顾合理利用。新西兰强调 “CAMLR 公约” 第二条规定的养护包括合理利用, 而不是说 “养护就是合理利用” [3]。对于此争论, 正如中国 学者唐建业所分析指出的, “CAMLR 公约” 第二条 的目的是为了在养护与利用之间实现一种平衡, 在 南极海洋保护区建设中不应排斥对南极生物资源的 可持续利用 [2]。

\section{四、对中国提升南极海洋保护区事务参与程 度的建议}

南极海洋保护区对于研究和应对全球气候变 化的影响、养护南极海洋生物多样性和生态环境具 有重要意义。但如果 “委员会” 在各方未就相关科 学、法律和政治等问题形成共识的情况下, 快速推 进建立超大面积、超长时限、严格管控的海洋保护 区, 势必引发疑虑和关切。这些疑虑包括: 在《南 极条约》暂时冻结南极主权主张的背景下, 西方发 达国家投入大量政治外交资源推动设立南极海洋保 护区, 是否在以海洋保护区为抓手强化南极海洋治 理主导权, 争夺南极事务管理权, 对南极海域实行 “软控制” ? 是否会通过设立海洋保护区, 加强对相 关海域的管控、提高他国参与门槛、限制他国南极 活动? 是否通过南极海洋保护区的外溢作用, 影响 国际法律规制的构建? 联合国正在开展国家管辖外 海域生物多样性 (BBNJ) 国际协定谈判, 包括公 海保护区在内的划区管理工具是该协定的一项重要 内容。为促进南极海洋保护区进程的顺利发展、保 障海洋保护区的养护绩效, “委员会” 各方应加强 科学、法律和政治等多个领域的对话和交流, 构建 更加坚实的法律和科学基础, 提升各项程序透明度。

中国是加强南极海洋治理和养护南极生态环境 的重要力量。中国不是南极领土主权主张国, 具有相 对超脱的政治地位, 且高度重视南极作为战略新疆 域在海洋命运共同体中的作用, 应在南极应对全球 气候变化、养护南极海洋生物多样性和保护生态环
境中发挥应有的作用、做出应有的贡献。自 2014 年 以来, 中国在南极海洋保护区事务上的立场发生转 变, 从 “应对” 转向 “积极参与” [12]。

\section{（一）深度参与南极海洋保护区事务}

南极治理事关人类共同福祉, 是国际治理的战 略新疆域, 受到中国的高度重视。习近平总书记指 出, 中方愿同国际社会一道, 更好认识南极、保护 南极、利用南极。2019 年 4 月, 习近平总书记提出 了 “海洋命运共同体” 重要理念, 指出中国高度重 视海洋生态文明建设, 保护海洋生物多样性。南极 是构建海洋命运共同体的重要内容。世界海洋在生 态方面存在密切关联性, 人类社会需携手共筑海洋 生态安全。海洋命运共同体是海洋生态文明的世界 版, 呼吁世界携手共建海洋生态文明, 在各国管辖 海域内加强生态环境治理, 在极地深海大洋等管辖 外海域积极参与全球海洋治理, 加强国际合作。

中国深度参与南极海洋保护区事务是此理念 的重要体现, 也是中国提升南极海洋治理话语权和 制度性权利的重要领域。中国是南极海洋生物资源 养护委员会的成员国, 依据 “CAMLR 公约” 参与 南极海洋保护区事务是中国的权利和义务。南极海 洋保护区在迅速发展的势头下仍存在很多问题和挑 战, 包括政治上进一步增信释疑、加强科学研究基 础、加强保护区制度建设、已建海洋保护区的科学 监测与绩效评估、新建保护区的设立标准、保护面 积与期限、保护措施的适宜性等, 这些都需要 “委 员会” 所有成员国共同应对。中国深度参与南极海 洋保护区事务既有现实需求, 又是海洋命运共同体 理念的应有之义。

\section{（二）尽快完善国内南极活动法规体系}

中国是南极条约协商国, 是《南极海洋生物养 护公约》缔约国, 在南极事务中发挥重要作用, 随着 中国南极事务的不断深入发展, 中国有责任将南极 条约体系的原则要求转化为国内法, 明晰部门的职 责, 规范相关主体的活动, 提升南极活动能力建设, 以推动中国南极事务进一步发展。为此, 2019 年 3 月, 第十三届全国人民代表大会常务委员会将 “南 极活动与环境保护法” 列入立法规划, 使我国在完 善国内南极活动法规体系方面向前迈出了重要一 步。为更加有效地参与南极海洋保护区事务, 为中 
国开展南极海洋保护区事务提供必要的法律制度保 障, 南极立法应包含南极保护区相关内容, 体现中 国对南极海洋保护区的立场、原则和中国企业及个 人遵守南极海洋保护区有关管理规定内容。一方面 加强与南极海洋保护区等公海保护区制度的国内法 衔接, 另一方面加强我国对南极条约体系法规的履 约遵约。

\section{（三）大力加强南极海洋生态环境科学研究}

科学依据是公海保护区建设的必备条件。公海 保护区从设计规划到运行管理、监测评估全过程需 要大量准确的信息数据作为决策依据。在长城站、 中山站、昆仑站和泰山站之后，中国第五个南极科 学考察站已选址南极洲罗斯海。中国应继续加强对 南极海洋生态环境的科学研究, 准确掌握罗斯海和 更广泛南极海域的生态环境状况和重要生物种群数 量, 精确把握南极海洋保护区未来发展走向, 为中 国争取更多话语权奠定科学研究基础, 也为提升南 极海洋保护区养护绩效提供公共产品和服务。

\section{参考文献}

[1] Commission for the Conservation of Antarctic Marine Living Resources. Report of the 23rd meeting of the commission [R]. Hobart: Commission for the Conservation of Antarctic Marine Living Resources, 2004.

[2] 唐建业. 南极海洋保护区建设及法律政治争论 [J]. 极地研究, 2016, 28(3): 370-380.

Tang J Y. The practice of establishing marine protected areas in the Southern Ocean and related legal and political debates $[\mathrm{J}]$. Chinese Journal of Polar Research, 2016, 28(3): 370-380.

[3] Commission for the Conservation of Antarctic Marine Living
Resources. Report of the 33rd meeting of the commission [R]. Hobart: Commission for the Conservation of Antarctic Marine Living Resources, 2014

[4] Commission for the Conservation of Antarctic Marine Living Resources. Report of the 38th meeting of the commission [R]. Hobart: Commission for the Conservation of Antarctic Marine Living Resources, 2019.

[5] Commission for the Conservation of Antarctic Marine Living Resources. Conservation measure 91-05 (2016)-Ross Sea region marine protected area [R]. Hobart: Commission for the Conservation of Antarctic Marine Living Resources, 2016.

[6] 陈力. 南极海洋保护区的国际法依据辨析 [J]. 复旦学报(社会科 学版), 2016 (2): 153-154.

Chen L. Study on the international legal bases of Antarctic Marine protected area [J]. Fudan Journal (Social Sciences Edition), 2016 (2): $153-154$

[7] Commission for the Conservation of Antarctic Marine Living Resources. Conservation measure 91-04 (2011)-general framework for the establishment of CCAMLR marine protected areas [R]. Hobart: Commission for the Conservation of Antarctic Marine Living Resources, 2011.

[8] 杨雷, 韩紫轩, 陈丹红, 等. 关于《建立CCAMLR海洋保护区的 总体框架》有关问题分析 [J]. 极地研究, 2014, 26(4): 522-534.

Yang L, Han Z X, Chen D H, et al. Analysis on the problems with the "general framework for the establishment of CCAMLR marine protected areas" [J]. Chinese Journal of Polar Research, 2014, 26(4): 522-534.

[9] Brady A M. New Zealand's strategic interests in Antarctica [J]. Polar Record, 2011, 47(2): 126-134.

[10] Smith D, Jabour J. MPAs in ABNJ: Lessons from two high seas regimes [J]. ICES Journal of Marine Science, 2018, 75(1): 417-425.

[11] Denzil M. Sustainable management in the Southern Ocean: CCAMLR science $[\mathrm{M}]$. Washington DC: Science Diplomacy: Antarctica, Science, and the Governance of International Spaces, 2011.

[12] Tang J Y. China's engagement in the establishment of marine protected areas in the Southern Ocean: From reactive to active [J]. Marine Policy, 2017, 75: 68-74. 